\title{
Debris flow risk mitigation by the means of rigid and flexible barriers - experimental tests and impact analysis
}

\author{
L. Canelli ${ }^{1}$, A. M. Ferrero ${ }^{1}$, M. Migliazza ${ }^{2}$, and A. Segalini ${ }^{1}$ \\ ${ }^{1}$ DICATeA, University of Parma, Italy \\ ${ }^{2}$ Dept. of Earth Science, University of Milan, Italy \\ Correspondence to: L. Canelli (luigi.canelli@nemo.unipr.it)
}

Received: 24 January 2012 - Revised: 19 April 2012 - Accepted: 20 April 2012 - Published: 24 May 2012

\begin{abstract}
The impact of a debris flow on a structure can have disastrous effects because of the enormous destructive potential of this type of phenomenon. Although the introduction of risk mitigation structures such as the Sabo Dam, the filter dam and more recently flexible barriers is usual, there are very few methods that are universally recognized for the safe design of such structures. This study presents the results of experimental tests, conducted with the use of a specifically created flume, in order to obtain detailed knowledge of the mechanical aspects, and to analyze the dynamics of the impact of a debris flow on different types of structures. The analyses of the tests, together with the calculation of the thrust caused by the flow, have made it possible to analyze the dynamics of the impact, which has shown differing effects, on the basis of the type of barrier that has been installed.
\end{abstract}

\section{Introduction}

Landslides triggered by rainfall occur in most mountainous areas. Most Alpine valleys are affected by soil slips and debris flows, which can be considered two of the most hazardous natural phenomena in Northern Italy. Debris flows usually occur as a result of intense rainfall, but other mechanisms, such as snow melting or dam break failure, can also trigger them. Debris flows in torrent catchment areas often produce much higher peak discharges than "ordinary" floods for the same rainfall conditions. Peak discharges often exceed the capacities of the channels on the fan, and this can result in widespread sediment disposition throughout the fan and possible dangers for buildings, infrastructures and people.
Flexible barriers, such as net barriers, have recently been used, especially in small basins, to control and mitigate debris flows (Ferrero et al., 2010; Roth et al., 2004). The similarities between these barriers and the protection measures used for rockfall events are quite remarkable. In some cases, structures installed for rockfall protection have, by chance, been impacted by debris flows, without losing their effectiveness (Segalini et al., 2008).

Although design and verification criteria for rockfalls are generally recognized and applied in Europe, no criteria have been introduced for debris flows. The need for new barrier certification methods, based on a good knowledge of the impact phenomenon and the connected energy, should be based on two fundamental considerations.

First, the different types of behaviour exhibited by debris flows and rock boulders impacting a barrier should be studied. In fact, while the impact of a falling rock on a net can be impulsive and punctual (a time domain of a few milliseconds), the interaction of a debris flow with a flexible barrier is more complex, and few recent studies have been conducted to help to understand the impact dynamics, to develop rigorous and useful guidelines, or to establish new verification criteria (Faug et al., 2009, 2010; Federico and Amoruso, 2009; Hübl et al., 2009; Teufelsbauer et al., 2009).

Second, the consequences of a failure of the barriers should be examined. When large debris events occur, a flexible barrier could fail and this could lead to catastrophic circumstances. In fact, a large volume of material can be stopped by a barrier, but should the barrier collapse, this volume could move and the disruptive potential of the flow would increase.

In order to clearly understand these impact phenomena, laboratory tests have been conducted in a small-scale 


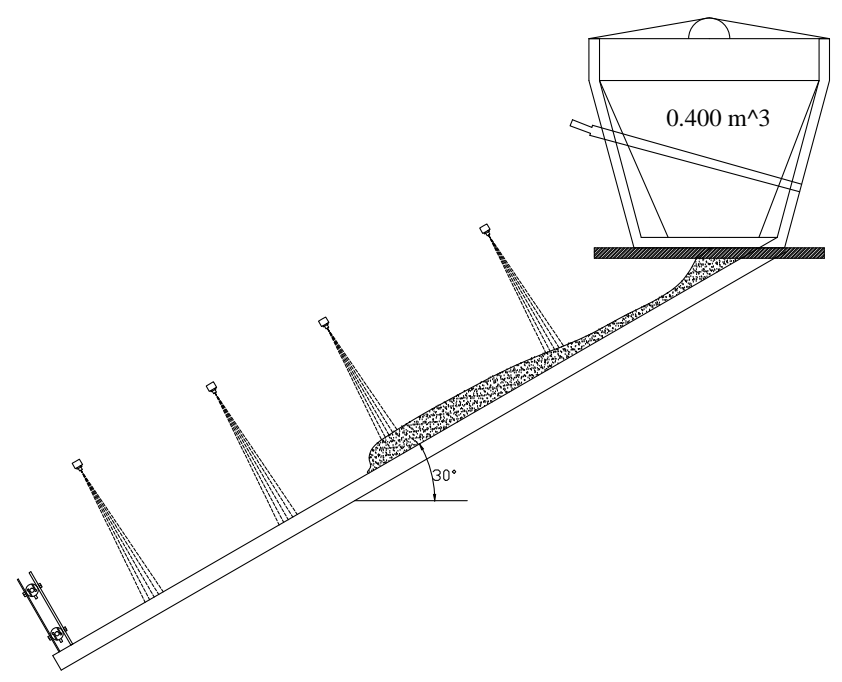

Fig. 1. Schematic representation of the flume. It was possible to install the barrier orthogonal to the bottom, as shown, or in a vertical position.

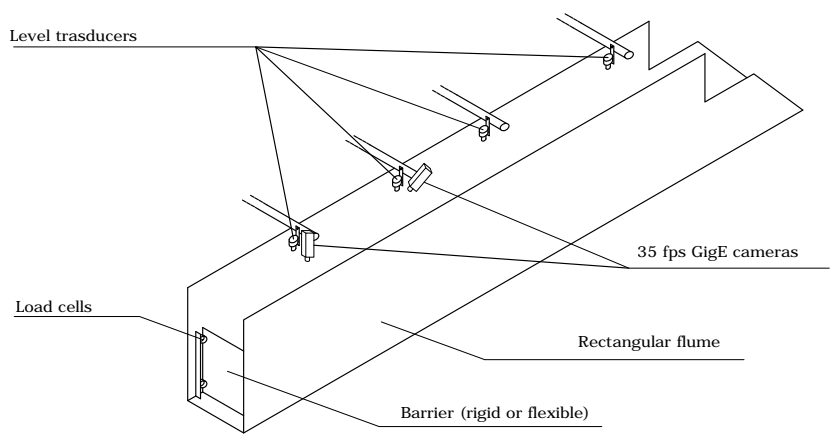

Fig. 2. Functional scheme of the flume.

channel, in which water-saturated sand flows were triggered. Different types of barriers (in terms of rigidity and shape) have been installed at the bottom of the channel in order to estimate the total thrust caused by the impact of the flow and to investigate the consequences of fast drainage when filter barriers are used. As shown in the tests, the water drainage induced by net barriers together with the absorption of energy due to the high deformation rates are able to significantly reduce the overpressure effects induced by the reflected wave after impact.

\section{Experimental apparatus and description of the tests}

The experimental apparatus consists of a flume, created with a $4 \mathrm{~m}$ long and $0.4 \mathrm{~m}$ wide steel bottom with a slope of $30^{\circ}$, in which saturated granular currents of known concentrations were triggered through the rapid emptying of a hopper, according to the scheme reported in Figs. 1 and 2.
Table 1. Main properties of the mixture used in the laboratory tests.

\begin{tabular}{lrr}
\hline Main Properties & & \\
\hline Mean Diameter & $\delta(\mathrm{m})$ & 0.001 \\
Friction Angle & $\Phi_{g}(\mathrm{deg})$ & 30 \\
Mass density of the grain & $\rho_{s}\left(\mathrm{~kg} \mathrm{~m}^{-3}\right)$ & 2550 \\
Mass density of the fluid & $\rho_{\mathrm{f}}\left(\mathrm{kg} \mathrm{m}^{-3}\right)$ & 1000 \\
Mass density of the mixture & $\rho_{\mathrm{m}}\left(\mathrm{kg} \mathrm{m}^{-3}\right)$ & 1930 \\
Solid volume fraction & $v_{\mathrm{S}}$ & 0.6 \\
Fluid volume fraction & $v_{\mathrm{f}}$ & 0.4 \\
Savage number & $N_{\text {Sav }}$ & 0.042 \\
Bagnold number & $N_{\text {Bag }}$ & 405 \\
Mass number & $N_{\text {mass }}$ & 3.85 \\
Darcy number & $N_{\text {Dar }}$ & 561 \\
Grain Reynolds number & $N_{\text {Rey }}$ & 105 \\
Friction number & $N_{\text {fric }}$ & 9646 \\
\hline
\end{tabular}

The main characteristics of the test material are listed in Table 1 , together with the mean value of six adimensional parameters, being representative of the reproduced phenomenon. According to Iverson's scaling theory (Iverson, 1997; Denlinger and Iverson, 2001), these adimensional parameters can be used to classify debris flows and identify their behaviour limits.

The grain-size distribution curve of the material is shown in Fig. 3.

The void ratio of the material (and therefore its density) was computed based on the amount of the material and water introduced into the hopper (approximately equal to 0.6); this implies that the void ratio is referred to the material condition before the test. The void ratio and its variation during the flow were not measured; however, its value is in good agreement with the data that can be found in The References(Mancarella and Hungr, 2010; Moriguchi et al., 2009).

Furthermore, the debris flow features during its flow phase are generally dilating (Takahashi, 1997) due to viscofrictional phenomena. This would induce a decrement in the density of the material, whilst, during the impact phase, the density increases again (Buchholtz and Pöschel, 1998); but such a value cannot be measured unless ultrasonic devices, specifically designed for density measurement, are used in the laboratory (Arattano and Franzi, 2003). Since no measurements of the density were carried out during this work, the assumption of an initial material density was the most realistic. No instrumentation was used for the measurement of the debris flow density along the channel, because the tests were performed specifically to study the impact conditions on the protection system, and not the evolution of the debris flow phenomena along its path.

The equipment that was used in the tests consisted of (a) four ultrasonic level measurers positioned in the centre line of the channel and at a known distance, with an acquisition frequency of $1 \mathrm{kHZ}$, and this was used to estimate the height and velocity of the impact of the debris front; 


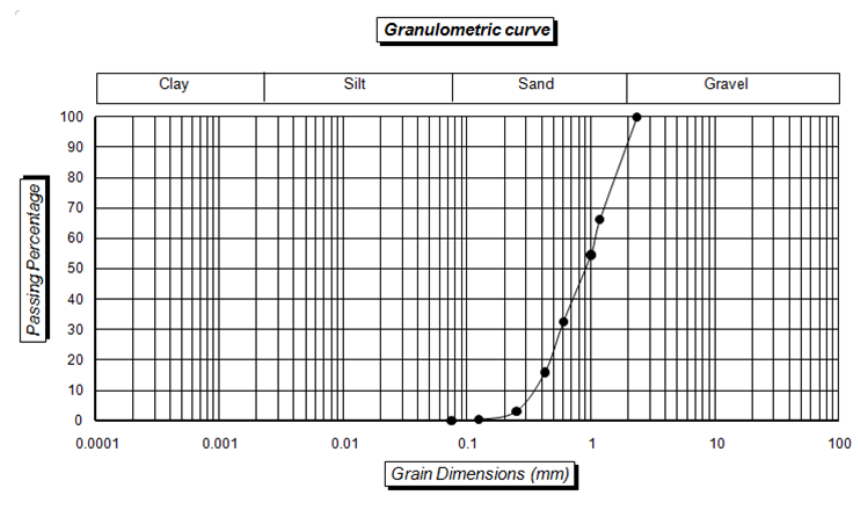

Fig. 3. Grain-size distribution curve of the sand utilized in the tests.

(b) two high definition (35 fps) GigE video cameras, synchronized through a specific hardware device, for the simultaneous acquisition of the impact from 2 different angles one from above, with the shooting plain parallel to the channel bottom (Camera 1), and the other (Camera 2) positioned below or above the barrier to monitor respectively the effects of rapid drainage or the evolution of the impact; and (c) four load cells installed in the vertices of the barrier, which made it possible to measure the thrust acting on the plate. This instrumented layout was preferred to the use of pressure sensors, in order to limit the effects of the intrusion of layers of air between the impacting wave and the rigid barrier. Bagnold (1939) analyzed this phenomenon, which can lead to the overestimation of the impact pressure at a local level.

The impact velocity of the flow was estimated through velocity values obtained using the level sensors and the values obtained from the analysis of the images.

The analysis of the images was conducted with National Instruments Vision Assistant software on the images acquired from Camera 1. The images were processed by recalibrating them in order to reduce the errors connected to lens distortion and to allow measurements to be made at a real magnitude. The software also allows for the calibration to be extended to all the different series of images, in order to be able to calculate the space covered by the debris flow at known intervals of time (1/35 of a second).

In the first phase of the laboratory activity, the barriers, which can be oriented towards the bottom of the channel, were positioned orthogonally to the channel bottom, in order to avoid the spin-off effects of the reflected vertical wave after the impact inside the channel.

Different types of barrier were used in the tests: the first type was made of rigid steel, with no draining, in order to correctly estimate the thrust and to be able to analyze the dynamics of the impact through the video images, and the second type was made of rigid steel with draining holes, in order to analyze the effects of rapid drainage of the material.
Finally, flexible barriers were used to verify whether and how the dynamics of the impact could vary after the deformation of the barrier.

\section{Laboratory tests and results}

The phenomenon of a debris impact against a structure has been analyzed in scientific literature; many empirical and non-empirical relations can in fact be found for the calculation of the dynamic thrust.

Armanini and Scotton (1993) investigated the impact mechanism of a debris flow using a rigid structure and they proposed the following formula for the case of a dam break and, as a consequence, for a height of the flow $\left(h_{0}\right)$ equal to the depth of the channel:

$S=9 \frac{1}{2} \gamma h_{0}^{2}$.

They concluded that the dynamic thrust can be estimated as 9 times the hydrostatic thrust of the impacting fluid.

On the other hand, the momentum balance for the calculation of the dynamic thrust, under the hypothesis that the flow can be assimilated to a homogeneous fluid and resolved for a control volume, makes it possible to conclude that the overpressure $\Delta p$, induced by the impact of the debris flow with the barrier in dynamic conditions, can be evaluated as follows:

$\Delta p=\rho_{\mathrm{m}} v^{2}$

where $\rho_{\mathrm{m}}$ is the mean density of the impacting fluid and $v$ is the velocity of this fluid; as a consequence, the modulus of the impacting force is

$F=\rho_{\mathrm{m}} v^{2} A$

where $A$ is the area of the section involved in the phenomenon and whose height should be considered as the height of the debris flow front.

Hungr and Kellerhals (1984) proposed correcting this value with a safety factor equal to 1.5 (that is, multiplying the height of the flow by 1.5 in order to take into consideration the formation of thrust wedges above the barrier):

$F=1.5 \rho_{\mathrm{m}} v^{2} A$.

It should be underlined that these expressions should be corrected, taking into consideration the angle of incidence of the flow with respect to the barrier, in order to evaluate the effective thrust component normal to the barrier itself.

Equation (3) can be rewritten in adimensional terms with respect to the hydrostatic thrust relative to the impacting front, obtaining 


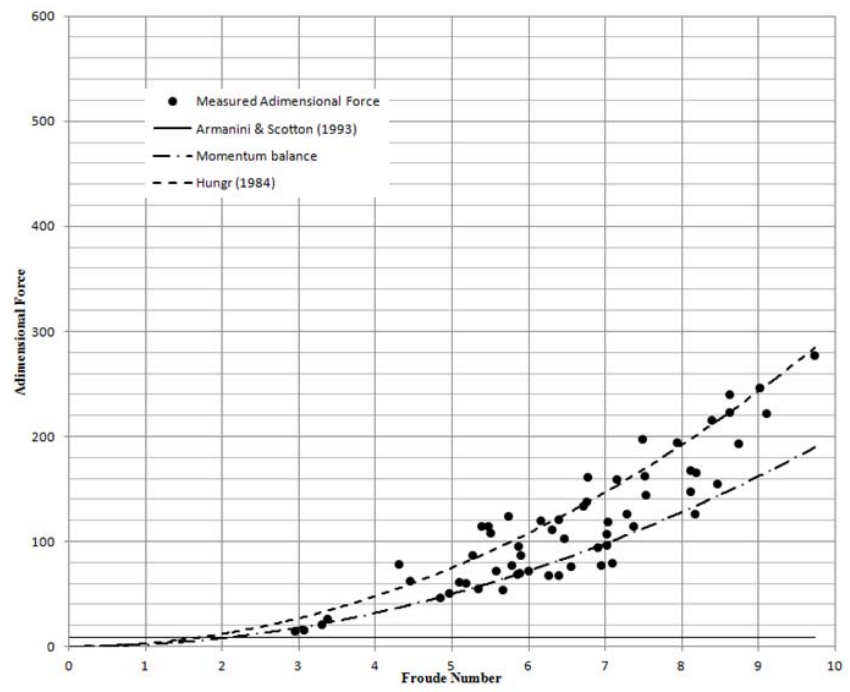

Fig. 4. Trend of the dimensionless force measured in function of the Froude number for barriers positioned orthogonal to the bottom of the channel.

$\tilde{F}=\frac{\rho_{\mathrm{m}} v^{2} A}{\frac{1}{2} \gamma_{\mathrm{m}} h_{\mathrm{f}}^{2}}=2 F r^{2}$

where $\gamma_{\mathrm{m}}$ is the specific weight of the fluid mixture and $h_{\mathrm{f}}$ is the height of the debris flow front.

The Froude number (i.e. the dimensionless value that describes different flow regimes of open channel flow as the ratio of inertial and gravitational forces) will therefore be calculated with respect to the debris flow front, whose impact on the barrier generates a pressure peak on the barrier itself.

\subsection{Rigid barriers}

Sixty tests were carried out in the laboratory on rigid barriers positioned both orthogonal to the channel bottom and vertical. The results presented in Fig. 4 show how the measured dimensionless thrust values fall between the values that can be obtained utilizing the Eq. (3) and those foreseen by Hungr and Kellerhals (1984) (Eq. 4).

Instead, the use of the quantum balance for channelized riverbeds and debris flows, with possible reflected waves, can lead to underestimations for vertical barriers. This is due to the formation of overpressures connected to the effect of the vertical reflected waves inside the channel. 38 analyzed tests in fact highlighted this concept (Fig. 5). Even when safety factors of 1.5 are considered, the design impact force could be underestimated.

The tests on rigid barriers, first positioned orthogonal to the bottom of the channel and then in a vertical position, have made it possible to conduct a detailed analysis on the evolution of the impact of a debris flow on a barrier.

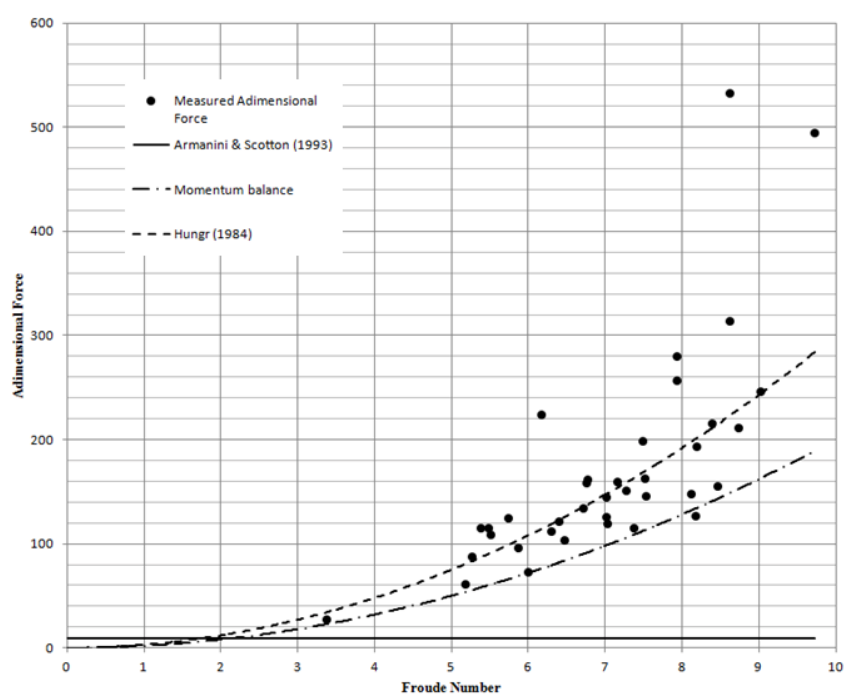

Fig. 5. Trend of the dimensionless force measured for tests conducted with vertical barriers.

The impact of the debris flow on the first rigid barrier allowed observation of the formation of a vertical jet-like wave, as already experimented by Armanini and Scotton (1993). As can be seen from the qualitative scheme shown in Fig. 6, the trend of the impact force in time does not present a single peak connected to the overpressure generated by the contact between the debris flow front (Fig. 6b) and the barrier, but two peaks. After the first impact, a vertical jet-like wave is created which, falling inside the channel (Fig. 6f), generates overpressure, which is then transformed into a further thrust that surpasses the one caused by the first impact of the debris flow front.

In temporal terms, it has been noted that the dispersion of the overpressure, induced by the effect of the reflected wave inside the channel, is about 10 times faster than the duration of the peak of the thrust induced by the debris flow on the structure: in the examined case, about 1/40 of a second compared to $1 / 4$.

It is also interesting to note that, although a vertical jetlike wave is also developed for filter barriers, in such conditions, the generated overpressure never exceeds the peak pressure generated by the impact of the debris flow front against the structure. This phenomenon could be due to the rapid drainage of the debris material with a consequent dissipation of the overpressure.

The images relative to the tests that were conducted with rigid barriers and filtrating rigid barriers, taken from the two different angles, can be found in Appendix A. It is possible to note how the maximum water flow, exiting from the opening of the filtrating barrier, occurs immediately after the effect of the reflection wave is felt inside the channel. 

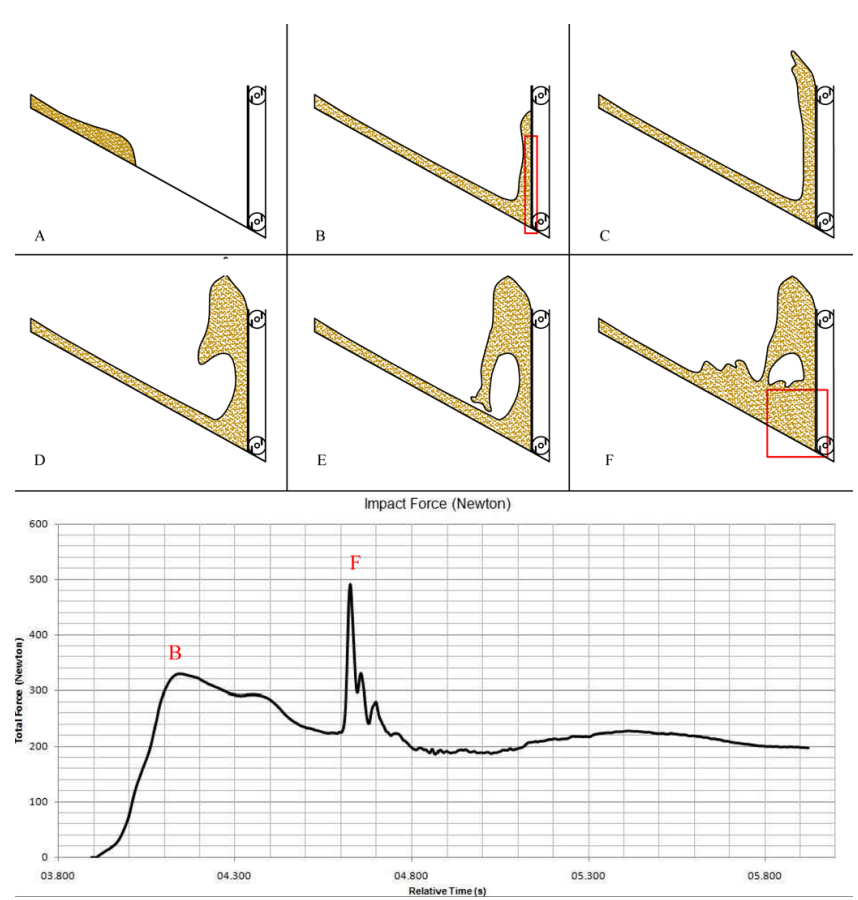

Fig. 6. Qualitative scheme of the evolution of the reflected wave and trend of the thrust measured in function of time.

\subsection{Rigid and flexible filter barriers}

The use of filter barriers has made it possible to analyze the evolution of the impact for the case of a rapid discharge of the mixture water.

The rigid barriers were made of steel plates with holes having a diameter of $10 \mathrm{~mm}$, coupled to a finer polyester mesh with an opening of $1 \mathrm{~mm}$, in order to ensure that all the test material was trapped. These barriers were installed vertically.

Although the formation of a jet-like wave was also observed for this type of barrier, the pressure peak that developed, due to its effect, never exceeded the peak of the impact of the debris flow front. This aspect is connected to the rapid dissipation of the pressures that built up inside the fluid component of the mixture and to the rapid discharge of the mixture water.

As can be seen in Fig. 7, the 32 analyzed tests show that although there are no effects worth mentioning, in terms of reduction in the peak thrust generated by the debris flow front, the values once again fall between the Hungr and Kellerhals (1984) formulation values and those established by Eq. (3).

The flexible barriers were made up of chicken wire, with a $1.5 \mathrm{~cm}$ opening, coupled to a polyester mesh. Elastic dissipater elements were arranged in order to support the chicken wire and were anchored to two steel cables placed above and below the barrier in order to allow a greater deformation in the centre of the barrier.

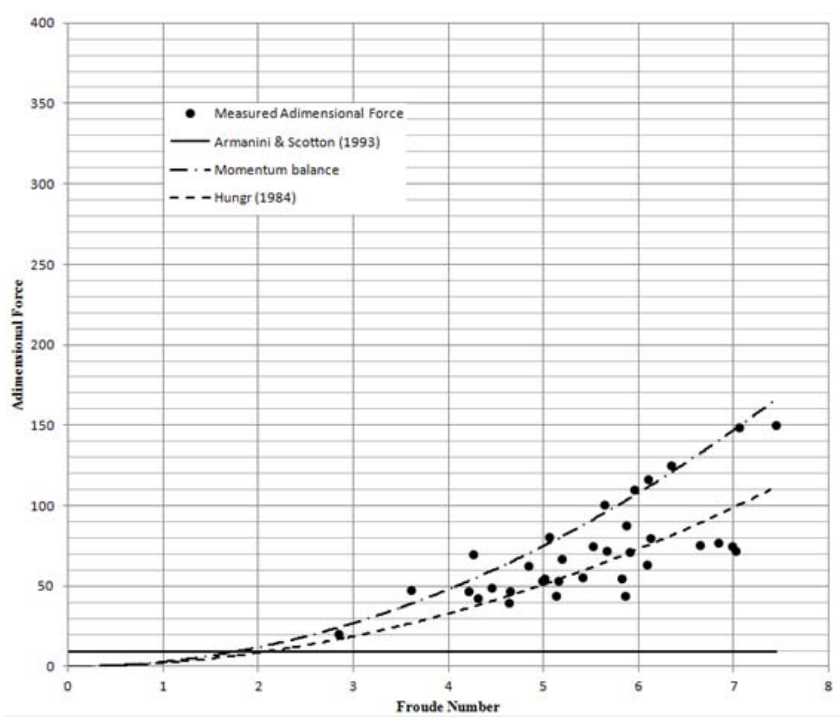

Fig. 7. Dimensionless thrust values measured for rigid barriers with holes.

A run-up of the material was also found in this case and, as a consequence, the reflected wave was kept inside the channel. Although it was not possible to measure the thrust that was actually distributed over the net, as it was not possible to estimate how much energy was absorbed by the dissipaters or by the deformation of the barrier itself, it is possible to conclude that, even in this case, the rapid discharge of the fluid portion of the mixture reduces the effects connected to wave overpressure.

\section{Conclusions}

This study had the purpose of investigating the dynamics of the impact of a debris flow on a protection structure and establishing which analytical model could be applied to estimate the thrust induced by a debris flow on a generic structure.

The setup of the experimental apparatus, although very simple, has allowed us to investigate the evolution of the impact and to estimate the thrust exerted by a debris flow on a rigid structure.

The tests conducted on rigid barriers have led to the conclusion that a debris flow thrust can be estimated using the equilibrium of the quantity of motion. However, Eq. (3) needs to be corrected with a suitable safety factor. The total thrust, distributed uniformly over the section influenced by the debris flow, can therefore be calculated using the following relation:

$F=k \rho_{\mathrm{m}} v^{2} A$

where $k$ is the safety factor, which should be varied between 1.5 and 5. 


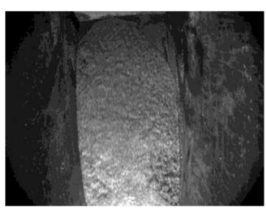

A

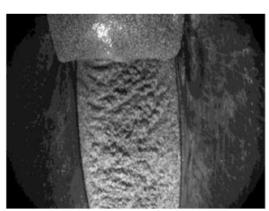

$\mathrm{D}$

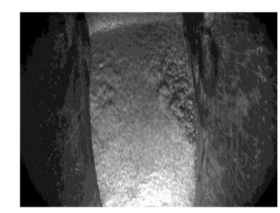

$\mathrm{B}$

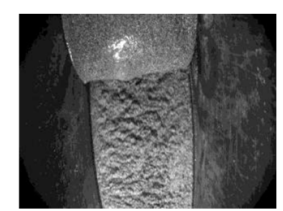

$\mathrm{E}$

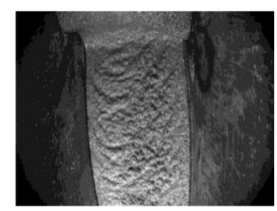

C

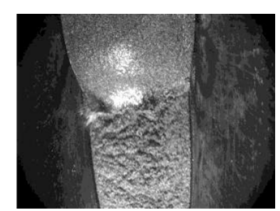

F
Fig. A1. Impact sequence, taken from Camera 1, for the rigid barrier vertically mounted (See Fig. 6). (A) debris flows at the onset of impact, (B) initial phase of the impact, (C) development of the vertical jet-like wave, (D) initial falling of the jet-like wave, (E) impact of the falling jet-like wave on the debris flow, (F) jet-like wave is completely fallen inside the channel.

This safety factor is connected to the possibility of the formation of a vertical jet-like wave after the impact. Although unlikely, the occurrence of such a phenomenon would lead to an underestimation of the design thrust value, and therefore to an incorrect design of the barrier.

For this reason, during the design phase, the type of flow (channelized, free surface) should be correlated to the type of barrier installed (rigid or filtering) and to the possibility of applying a homogeneous fluid scheme.

The impact of single or multiple masses of large dimensions (boulders) could in fact generate impulsive forces on the barrier of some orders of magnitude higher than those estimated utilizing an equivalent fluid scheme, as already proposed by Hungr and Kellerhals (1984). In this context, deformable barriers allow a reduction of the impulsive effects of these blocks, thanks to the larger contact surface between the impacting mass and the net. However, this contribution still needs to be quantified and this will be the subject of future studies.

\section{Appendix A}

\section{Image sequences}

The image sequences shown below were obtained using the two GigE cameras, synchronized by an impulse generator hardware device, in order to visualize the impact from two different points of view at the same time-step with a maximum error of 2 milliseconds.

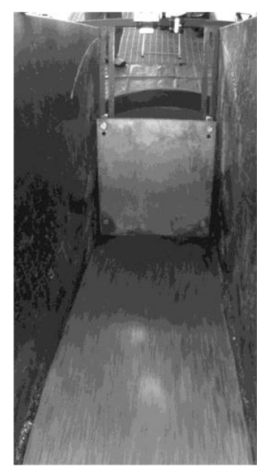

A

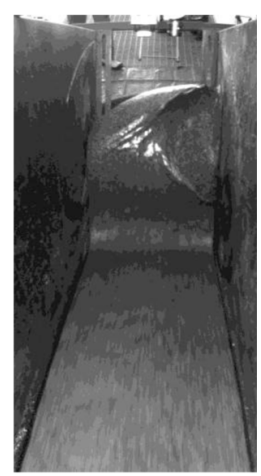

$\mathrm{D}$

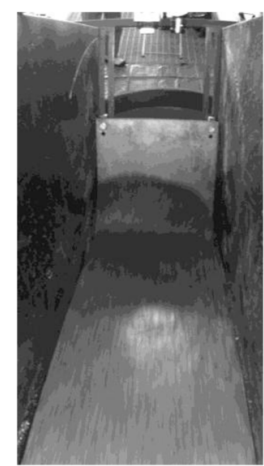

B

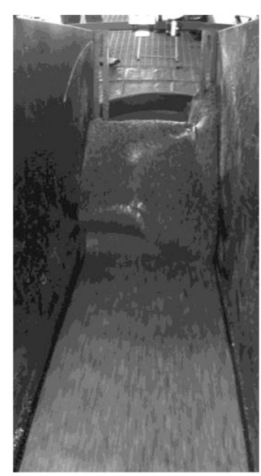

E

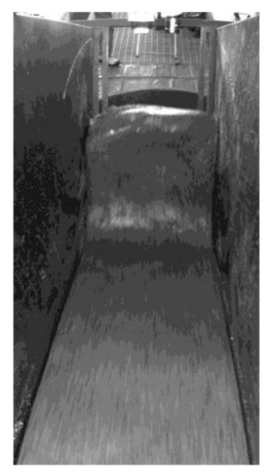

C

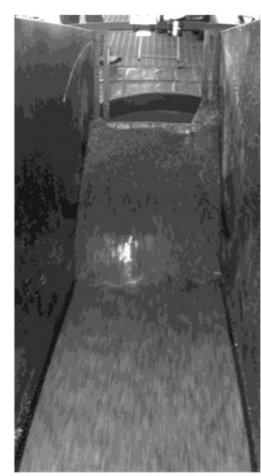

$\mathrm{F}$
Fig. A2. Impact sequence, taken from Camera 2, for the rigid barrier vertically mounted (See Fig. 6). (A) debris flows at the onset of impact, (B) initial phase of the impact, (C) development of the vertical jet-like wave, (D) initial falling of the jet-like wave, (E) impact of the falling jet-like wave on the debris flow, (F) jet-like wave is completely fallen inside the channel.

Impact sequence for a rigid vertical barrier - Camera 1 (Fig. A1a-f).

Impact sequence for a rigid vertical barrier - Camera 2 (Fig. A2a-f).

Impact sequence for a rigid draining barrier - Camera 1 (Fig. A3a-f).

Impact sequence for a rigid draining barrier - Camera 2 (Fig. A4a-f).

Acknowledgements. This study has been financed by ICE D.R. 975 del 26/11/2009 from the Minister of Economic Development.

Edited by: M. Arattano

Reviewed by: C. Deangeli and another anonymous referee 


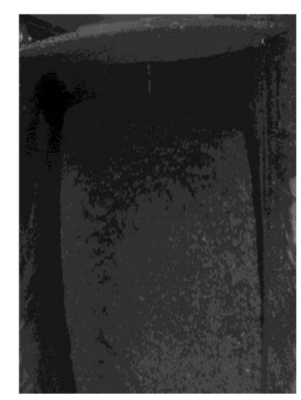

A

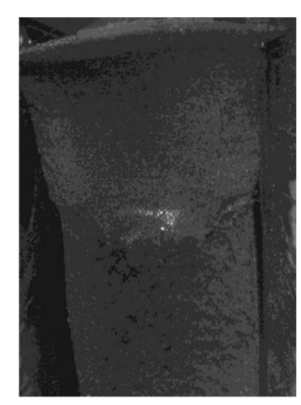

D

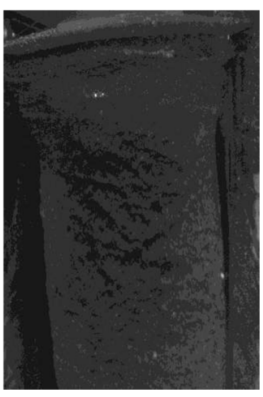

B

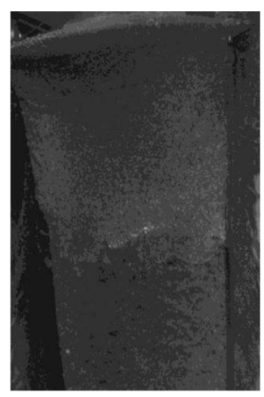

E

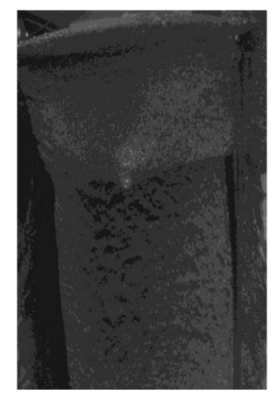

C

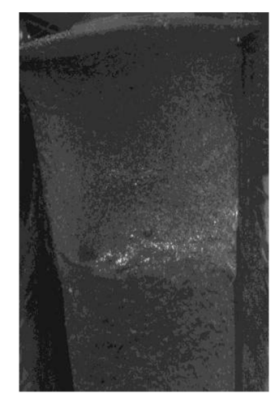

F

Fig. A3. Impact sequence, taken from Camera 1, for the rigid draining barrier vertically mounted. (A) debris flows at the onset of impact, (B) initial phase of the impact, (C) development of a very small vertical jet-like wave, (D-F) the small jet-like wave returns inside the channel without any considerable increment of the pressure peak.

\section{References}

Arattano, M. and Franzi, L.: On the evaluation of debris flows dynamics by means of mathematical models, Nat. Hazards Earth Syst. Sci., 3, 539-544, doi:10.5194/nhess-3-539-2003, 2003.

Armanini, A. and Scotton, P.: On the dynamic impact of a debris flow on structures, Proceedings of XXV Congress IAHR, Tokyo (Tech. Sess. B, III), 203-210, 1993.

Bagnold, R. A.: Interim report on wave-pressure research, J. Inst. Civil Eng., 12, 201-226, 1939.

Buchholtz, V. and Pöschel, T: Interaction of a granular stream with an obstacle, Granul. Matter, 1, 33-41, 1998.

Denlinger, R. P. and Iverson, R. M.: Flow of variably fluidized granular masses across a three dimensional terrain 2, Numerical predictions and experimental tests, J. Geophys. Res., 106, 553-566, 2001.

Faug, T., Beguin, R., and Chanut, B.: Mean steady granular force on a wall overflowed by free surface gravity-driven flows in steady and unsteady states, Phys. Rev. E, 80, 021305, 2009.

Faug, T., Chanut, B., Beguin, R., Naaim, M., Thibert, E., and Baroudi, D.: A simple analytical model for pressure on obstacles induced by snow avalanches, Ann. Glaciol., 51, 1-8, 2010.

Federico, F.: Amoruso Impact between fluids and solids. Comparison between analytical and FEA results, Int. J. Impact Eng., 36, 154-164, 2009.

Ferrero, A. M., Giani, G. P., and Segalini, A.: Numerical and experimental analysis of debris flow protection fence efficiency, Eu-

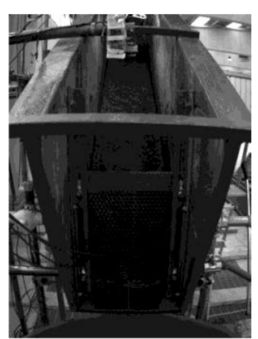

A

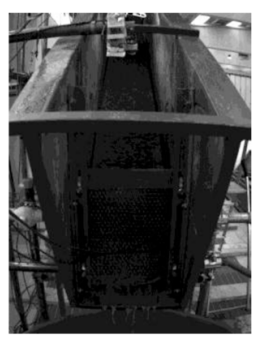

$\mathrm{D}$

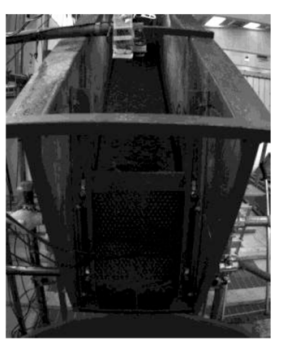

B

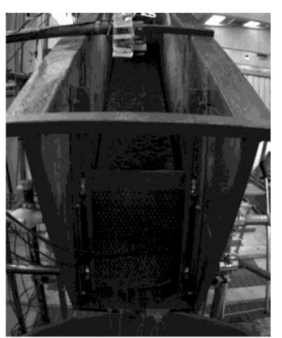

$\mathrm{E}$

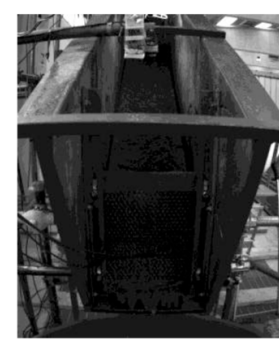

C

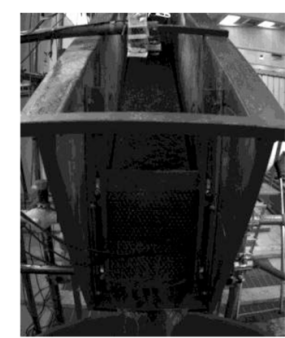

$\mathrm{F}$
Fig. A4. Impact sequence, taken from Camera 2, for the rigid draining barrier vertically mounted. (A) debris flows at the onset of impact, (B) initial phase of the impact, (C) development of a very small vertical jet-like wave, (D-F) the small jet-like wave returns inside the channel without any considerable increment of the pressure peak.

rock, 2010 Lausanne, 2010.

Hübl, J., Suda, J., Proske, D., Kaitna, R., and Scheidl, C.: Debris Flow Impact Estimation. International Symposium on Water Management and Hydraulic Engineering Ohrid/Macedonia, Paper A56, 1-5 September 2009, available at: http://wmhe.gf.ukim.edu.mk/Downloads/PapersTopic1/ A56-Hubl-Suda-Proske-Kaitna-Scheidl.pdf, 2009.

Hungr, O., Morgan, G. C., and Kellerhals, R.: Quantitative analysis of debris torrent hazard for design of remedial measures, Canadian Geotech. J., 21, 663-677, doi:10.1139/t84-073, 1984.

Iverson, R. M.: The physics of debris flows, Rev. Geophys., 35, 245-296, 1997.

Mancarella, D. and Hungr, O.: Analysis of run-up of granular avalanches against steep, adverse slopes and protective barriers, Can. Geotech. J., 47, 827-841, 2010.

Moriguchi, S., Borja, R. I., Yashima, A., and Sawada, K.: Estimating the impact force generated by granular flow on a rigid obstruction, Acta Geotech., 4, 57-71, 2009.

Roth, A., Kästli, A., and Frenez, Th.: Debris Flow Mitigation by Means of Flexible Barriers, Proc. Int. Symp. Interpraevent, Riva del Garda, Italy, Klagenfurt: Interpraevent, 2004.

Segalini, A., Giani, G. P., and Ferrero, A. M.: Analisi dell'efficienza di barriere di protezione contro la caduta massi e le colate di detrito, Rendiconti online Soc. Geol. It., 2, 1-3, 2008.

Takahashi, T.: Debris flows: mechanics, prediction and countermeasures, Taylor and Francis, London, 2007.

Teufelsbauer, H., Wang, Y., Chlou, M. C., and Wu, W.: Flowobstacle interaction in rapid granular avalanches: DEM simulation and comparison with experiment, Granul. Matter, 11, 209$222,2009$. 